\title{
ANALISIS POLA SPASIAL PERSEBARAN \\ KAWASAN LAHAN PERTANIAN PANGAN BERKELANJUTAN DI KABUPATEN KARAWANG
}

\author{
Ranti Marinda ${ }^{1}$, Santun R.P. Sitorus ${ }^{2}$, Didit Okta Pribadi ${ }^{3}$ \\ 1Program Studi Ilmu Perencanaan Wilayah, Faperta, Institut Pertanian Bogor \\ Jalan Meranti, Kampus IPB Dramaga, Bogor, Jawa Barat, 16680, Indonesia \\ 2Departemen Ilmu Tanah dan Sumberdaya Lahan, Faperta, Institut Pertanian Bogor \\ Jalan Meranti, Kampus IPB Dramaga Bogor, Jawa Barat, 16680, Indonesia \\ 3Pusat Konservasi Tumbuhan Kebun Raya Bogor, LIPI \\ Jalan Ir H Juanda No 13, Bogor Tengah, Jawa Barat, 16122, Indonesia \\ e-mail: ranti.marinda@gmail.com
}

Diterima: 28 Maret 2020, Direvisi: 03 April 2020, Disetujui: 20 Juni 2020

\begin{abstract}
Abstrak
Kabupaten Karawang merupakan contoh wilayah yang menghadapi dualisme peran sebagai hinterland 2 kawasan metropolitan (Jabodetabek dan Cekungan Bandung) sekaligus sebagai salah satu lumbung padi nasional. Penetapan rencana tata ruang dan penetapan luasan serta lokasi Lahan Pertanian Pangan Berkelanjutan (LP2B) telah dilakukan untuk merespon dualisme peran tersebut. Penetapan Kawasan LP2B menjadi menarik untuk diteliti, khususnya terkait persebaran pola spasialnya melalui metode autokorelasi spasial. Penelitian ini bertujuan untuk dapat menunjukkan pola hubungan atau korelasi antarlokasi, serta menganalisis faktor-faktor pendorong terjadinya korelasi tersebut. Analisis autokorelasi spasial yang dilakukan menghasilkan kesimpulan bahwa terdapat autokorelasi spasial bersifat positif dengan pola sebaran mengelompok (clustered), yang didefinisikan dalam 2 tipologi hubungan pengelompokan yaitu high-high dan lowlow. Hubungan yang terjadi pada persebaran luasan Kawasan LP2B ini membuktikan adanya pengaruh rencana tata ruang dalam mengatur fungsi kawasan di Kabupaten Karawang. Penetapan Kawasan LP2B telah mengadaptasi perkembangan kutub-kutub pertumbuhan ekonomi non-pertanian secara keruangan, yang disesuaikan dengan penggunaan lahan saat ini.
\end{abstract}

Kata kunci: autokorelasi spasial, kutub pertumbuhan ekonomi, LISA, LP2B, Moran's

\begin{abstract}
Karawang Regency faces dualism as a hinterland of 2 metropolitan area (Jabodetabek and Cekungan Bandung), as well as a national rice barn. Determination of the spatial plan and determination of the extent and location of the distribution of Sustainable Food Agricultural Land (LP2B) has been carried out to respond the role dualism. The determination of $L P 2 B$ area is interesting to study, especially in relation to the spatial pattern distribution through the spatial autocorrelation method. This study aims to be able to show the pattern of relationships or correlations between locations, and analyze the driving factors of correlation. Spatial autocorrelation analysis concluded that there is a positive spatial autocorrelation with clustered patterns, which are defined in 2 typologies of grouping relationships namely high-high and low-low. The relationship that occurred in the distribution of $L P 2 B$ area proved the influence of spatial plan in regulating the function
\end{abstract}


of area in Karawang Regency. Establishment of the LP2B Area adapted non-agricultural economic growth poles, which are adapted to current land use.

Key words: spatial autocorrelation, economic growth poles, LISA, LP2B, Moran's

\section{PENDAHULUAN}

Merujuk pada ketentuan menimbang yang pertama dalam UndangUndang Nomor 26 Tahun 2007 tentang Penataan Ruang, lahan dipandang sebagai suatu sumberdaya yang perlu mendapat pengelolaan secara bijaksana agar berdaya guna dan berhasil guna dengan berpedoman pada kaidah penataan ruang, sehingga kualitas ruang pada suatu wilayah dapat terjaga keberlanjutannya demi terwujudnya kesejahteraan umum dan keadilan sosial sesuai landasan konstitusional UndangUndang Dasar Negara Republik Indonesia Tahun 1945. Luasan lahan tidak akan bertambah namun kualitas lahan dapat menurun akibat tindakan eksploitatif manusia, serta jumlah penduduk yang akan terus bertambah termasuk kebutuhannya. Hal ini menyadarkan para pihak untuk melakukan penyelenggaraan penataan ruang yang transparan, efektif, dan partisipatif agar terwujud ruang hidup yang aman, nyaman, produktif, dan berkelanjutan.

Lahan yang kerap kali terancam untuk berubah fungsi sebagai akibat dari desakan kebutuhan manusia adalah lahan pertanian. Menurut Kustiwan (1997) dan Wahyunto (2009), terjadi penurunan luas baku lahan sawah di Indonesia yang signifikan dalam kurun waktu 25 tahun (1984-2009) dan dipastikan terus menurun dari angka sekitar 8,3 juta ha pada tahun 1990 menjadi 7,1 juta ha pada tahun 2018 (BPS RI, 1990 dan 2018). Lahan sawah selalu menjadi sasaran utama dalam kasus alih fungsi lahan, karena sewa tanah (land rent) pertanian senantiasa paling rendah dibanding sewa tanah (land rent) aktivitas sektor non pertanian (Pribadi et al., 2017). Sementara itu, lahan pertanian memiliki peran dan fungsi strategis bagi masyarakat Indonesia yang bercorak agraris karena penduduk Indonesia usia 15 tahun ke atas, paling banyak menggantungkan hidup pada sektor pertanian yaitu sebesar 28,8\% (BPS RI, 2019).

Kabupaten Karawang merupakan contoh wilayah yang menghadapi dualisme peran sebagai hinterland 2 kawasan metropolitan (Jabodetabek dan Cekungan Bandung) sekaligus sebagai salah satu lumbung padi nasional. Peran tersebut menjadi tantangan sekaligus ancaman bagi perkembangan wilayahnya, baik dalam hal sosial, ekonomi, maupun fisik lingkungan. Pemerintah Pusat dan Pemerintah Daerah Kabupaten Karawang menyadari kenyataan tersebut, sehingga berusaha bersinergi dalam melaksanakan amanat UndangUndang Nomor 26 Tahun 2007 tentang Penataan Ruang dan Undang-Undang Nomor 41 Tahun 2009 tentang Perlindungan Lahan Pertanian Pangan Berkelanjutan, salah satunya melalui penetapan rencana tata ruang termasuk penyusunan instrumen pengendalian pemanfaatan ruang, serta penetapan luasan dan lokasi persebaran Lahan Pertanian Pangan Berkelanjutan (LP2B).

Data luas sawah baku tahun 2018 berdasarkan data SK Menteri Agraria dan Tata Ruang/Kepala Badan Pertanahan Nasional No. 399/Kep-23.3/X/2018 tentang Persebaran Luasan Sawah Baku Indonesia Tahun 2018 (Gambar 1), digunakan sebagai basis data dalam menyusun rencana kawasan LP2B sebagaimana merupakan peraturan turunan dari Peraturan Daerah Kabupaten Karawang Nomor 1 Tahun 2018 tentang Perlindungan Lahan Pertanian Pangan Berkelanjutan (Gambar 2). Luas sawah baku tahun 2018 sebesar 102.144 ha. 
Berdasarkan informasi dari Dinas Pertanian Kabupaten Karawang, terdapat pertimbangan aspek legal penguasaan tanah dan aspek sosial, ekonomi, serta politis lain yang mempengaruhi ketetapan kawasan LP2B. Terdapat selisih antara luas sawah baku tahun 2018 dengan luas seluruh wilayah LP2B (97.866 ha), yaitu sebesar 4.278 ha yang berarti bahwa akan terjadi alih fungsi lahan sawah. Perubahan luasan sawah baku tahun 2018 menjadi Kawasan LP2B untuk setiap wilayah kecamatan diilustrasikan dalam diagram batang pada Gambar 3. Berdasarkan Gambar 3, terdapat anomali pada 7 kecamatan (Cibuaya, Cilamaya Wetan, Cilebar, Pakisjaya, Pedes,
Tegalwaru, dan Tirtajaya), dengan luasan Kawasan LP2B lebih besar dari pada luas sawah baku tahun 2018. Secara geografis, 7 kecamatan ini berada pada bagian utara dan selatan Kabupaten Karawang yang penggunaan lahannya didominasi dan dikelilingi oleh pertanian. Diketahui pula bahwa kecamatan yang mengalami penurunan luasan berada pada bagian tengah Kabupaten Karawang, yang penggunaan lahannya didominasi oleh permukiman perkotaan dan industri, serta berdekatan dengan sarana transportasi primer.

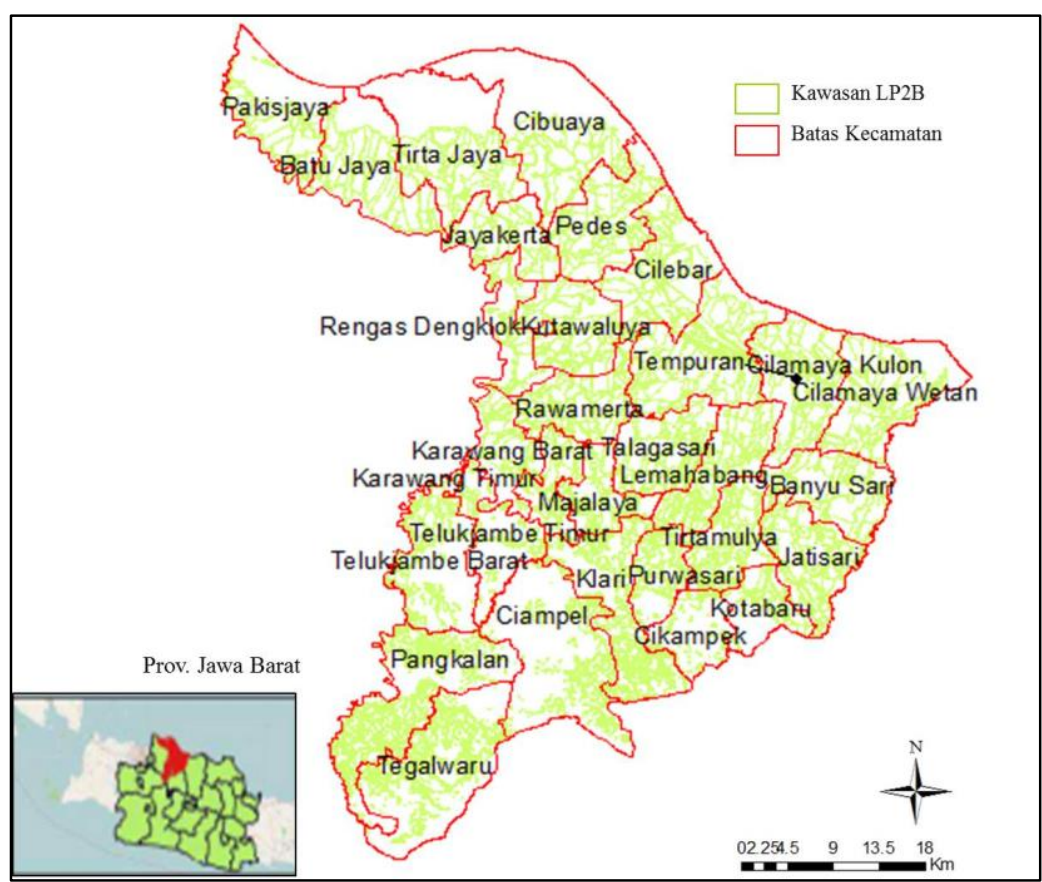

sumber: Kementerian Agraria dan Tata Ruang, BPN (2018)

Gambar 1. Peta Persebaran Sawah Baku Tahun 2018

Luasan Lahan Pertanian Pangan Berkelanjutan (LP2B) yang telah ditetapkan secara legal dianggap sebagai bentuk jaminan hak atas pangan bagi setiap warga negara Indonesia, namun demikian hal ini kontradiktif jika dinilai dari sudut pandang sumber pekerjaan dan penghidupan yang layak bagi petani atau pihak-pihak yang mengusahakan lahan pertanian. Petani menjadi pihak yang senantiasa kurang diuntungkan karena nilai jual produknya yang relatif lebih murah jika dibandingkan sumber pangan lainnya.

Penetapan Kawasan LP2B oleh Pemerintah Daerah Kabupaten Karawang menjadi menarik untuk diteliti, khususnya terkait persebaran pola spasialnya. Relevansi penetapan kawasan tersebut terhadap tekanan aktifitas perekonomian 
non-pertanian yang tumbuh di Kabupaten Karawang memerlukan analisis secara keruangan. Metode yang dipilih dalam menganalisis pola spasial Kawasan LP2B ini yaitu metode autokorelasi spasial.
Penelitian ini bertujuan untuk dapat menunjukkan pola hubungan atau korelasi antar lokasi, serta menganalisis faktorfaktor pendorong terjadinya korelasi tersebut.

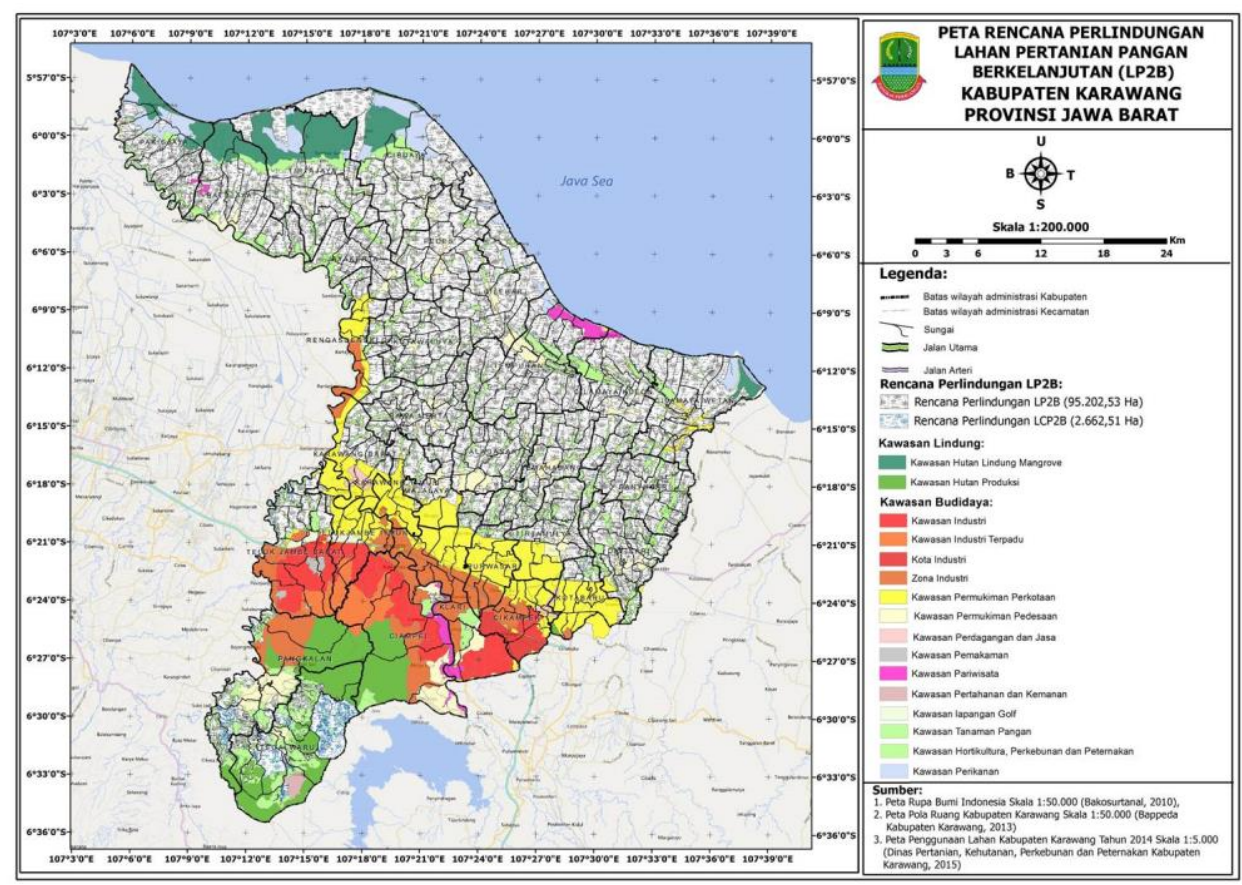

Sumber: Dinas Pertanian Kabupaten Karawang (2019)

Gambar 2. Peta Rencana LP2B Kabupaten Karawang

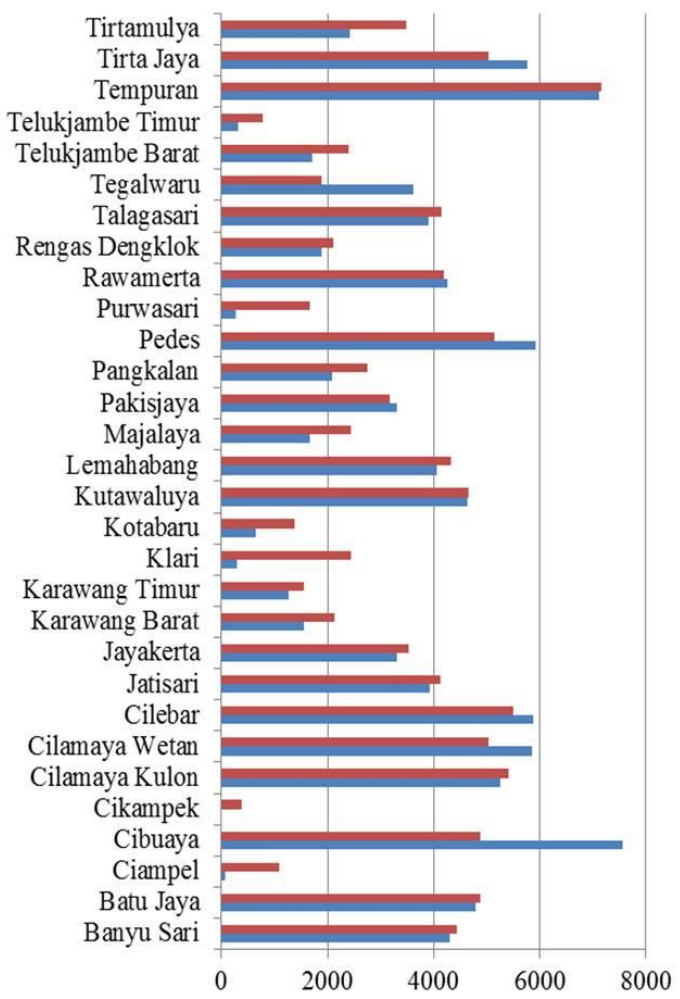

- Luas sawah Th. 2018

- Luas sawah dalam kawasan LP2B

Gambar 3. Perubahan Luasan Sawah Baku Tahun 2018

Menjadi Kawasan LP2B Berdasarkan Wilayah Kecamatan 


\section{METODE PENELITIAN}

Wilayah dan Data Penelitian

Penelitian ini dilakukan di

Kabupaten Karawang yang lokasinya berada pada bagian utara Provinsi Jawa Barat yang secara geografis terletak antara 107002 - 107040` Bujur Timur dan 5056` 6034` Lintang Selatan. Kabupaten Karawang terdiri atas 30 kecamatan (Gambar 4). Luas wilayah Kabupaten Karawang yaitu 175.327 ha atau 3,73\% dari luas Provinsi Jawa Barat (BPS Kabupaten Karawang, 2018). Secara geografis, Kabupaten Karawang berbatasan dengan Laut Jawa di bagian utara,
Kabupaten Subang di bagian timur, Kabupaten Bogor dan Kabupaten Purwakarta di bagian selatan, serta Kabupaten Bekasi di bagian barat. Penelitian ini menggunakan jenis data sekunder yang bersumber dari Badan Perencanaan dan Pembangunan Daerah dan Kantor Pertanahan Kabupaten Karawang. Data tersebut terdiri atas data peta administrasi wilayah Kabupaten Karawang dan peta rencana Kawasan LP2B, termasuk data luasan LP2B pada masing-masing kecamatan (Tabel 1).
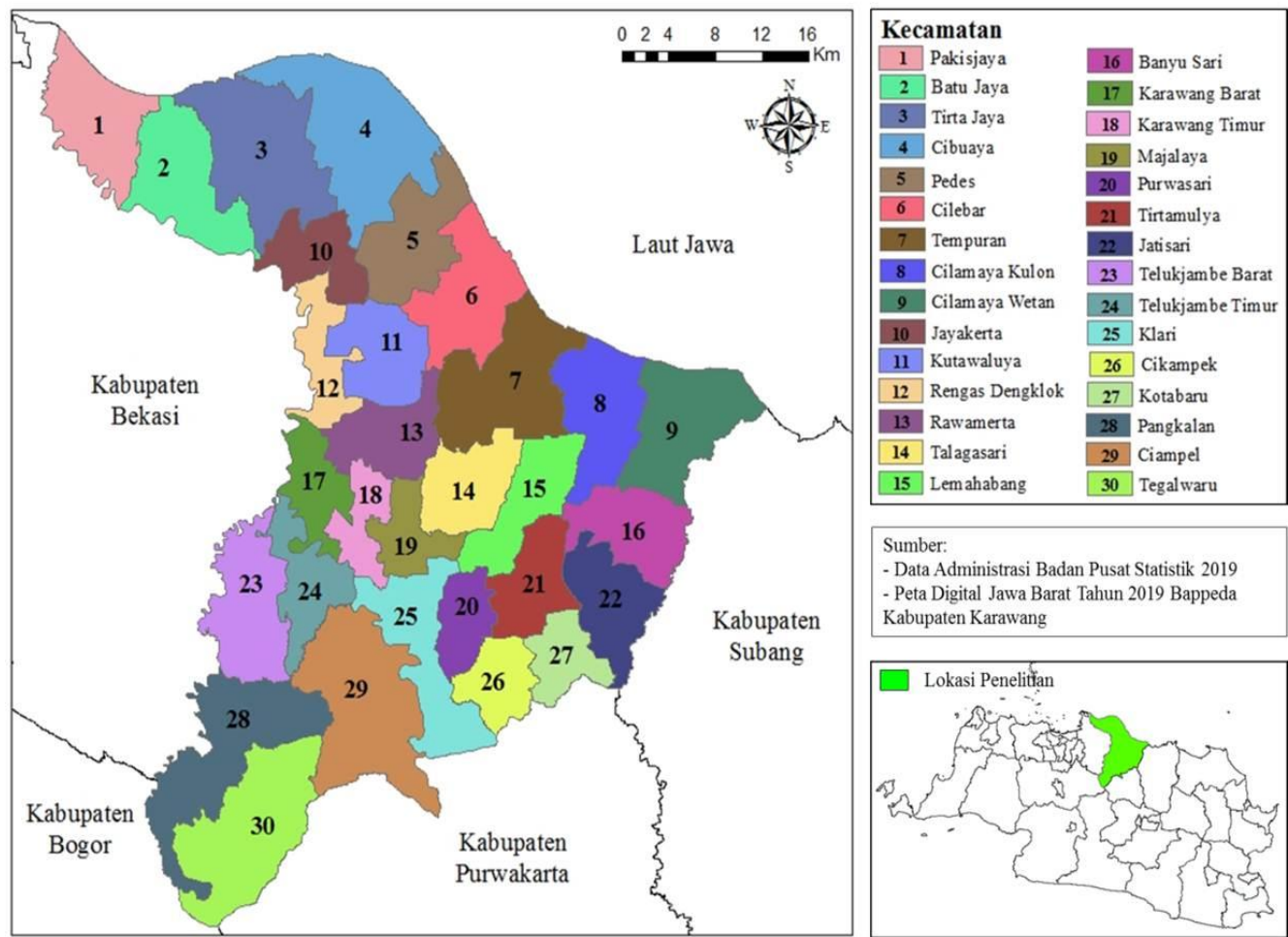

Gambar 4 Peta Administrasi Wilayah Kabupaten Karawang

Tabel 1. Luasan Kawasan LP2B Berdasarkan Kecamatan di Kabupaten Karawang

\begin{tabular}{clr}
\hline No & Kecamatan & Rencana LP2B (ha) \\
\hline 1 & Banyusari & 4.305 \\
2 & Batujaya & 4.788 \\
3 & Ciampel & 67 \\
4 & Cibuaya & 7.546 \\
5 & Cikampek & - \\
6 & Cilamaya Kulon & 5.246 \\
7 & Cilamaya Wetan & 5.825 \\
8 & Cilebar & 5.884 \\
9 & Jatisari & 3.935 \\
10 & Jayakerta & 3.312 \\
\hline
\end{tabular}


Tabel 1 (Lanjutan)

\begin{tabular}{clr}
\hline No & \multicolumn{1}{c}{ Kecamatan } & Rencana LP2B (ha) \\
\hline 11 & Karawang Barat & 1.559 \\
12 & Karawang Timur & 1.262 \\
13 & Klari & 283 \\
14 & Kotabaru & 627 \\
15 & Kutawaluya & 4.638 \\
16 & Lemahabang & 4.054 \\
17 & Majalaya & 1.659 \\
18 & Pakisjaya & 3.313 \\
19 & Pangkalan & 1.784 \\
20 & Pedes & 5.915 \\
21 & Purwasari & 268 \\
22 & Rawamerta & 4.251 \\
23 & Rengasdengklok & 1.881 \\
24 & Talagasari & 3.900 \\
25 & Tegalwaru & 1.493 \\
26 & Telukjambe Barat & 1.565 \\
27 & Telukjambe Timur & 309 \\
28 & Tempuran & 7.122 \\
29 & Tirtajaya & 5.767 \\
30 & Tirtamulya & 2.425 \\
\hline & Jumlah & 97.866 \\
\hline
\end{tabular}

Sumber: Dinas Pertanian Kabupaten Karawang (2019)

\section{Analisis Data Spasial}

Penelitian ini akan menggunakan peta persebaran LP2B di Kabupaten Karawang dengan unit analisis batas administratif kecamatan (Gambar 4). Peta digunakan untuk menentukan hubungan kedekatan antar kecamatan di Kabupaten Karawang, dengan demikian akan lebih mudah memberikan pembobotan pada masing-masing lokasi atau kecamatan. Kabupaten Karawang terdiri atas 30 kecamatan, sehingga matriks pembobotan akan berukuran $30 \times 30$. Menurut Kosfeld dan Dreger (2006), grid umum ketetanggaan dapat didefinsikan dalam 3 cara, yaitu:

1. Rook Contiguity

Daerah pengamatannya ditentukan berdasarkan sisi-sisi yang saling bersinggungan dan bagian sudut tidak diperhitungkan. Ilustrasi Rook Contiguity dilihat pada Gambar 5, dimana unit B1, B2, B3, dan B4 merupakan tetangga dari unit $\mathrm{A}$.

2. Bishop Contiguity

Daerah pengamatannya ditentukan berdasarkan sudut-sudut yang saling bersinggungan dan bagian sisi tidak diperhitungkan. Ilustrasi untuk Bishop Contiguity dilihat pada Gambar 5, dimana unit $\mathrm{C} 1, \mathrm{C} 2, \mathrm{C} 3$, dan $\mathrm{C} 4$ merupakan tetangga dari unit $\mathrm{A}$.

3. Queen Contiguity

Daerah pengamatannya ditentukan berdasarkan sisi-sisi yang saling bersinggungan dan bagian sudut juga diperhitungkan. Ilustrasi untuk Queen Contiguity dapat dilihat pada Gambar 5, dimana unit B1, B2, B3, dan B4 serta $\mathrm{C} 1, \mathrm{C} 2, \mathrm{C} 3$, dan C4 merupakan tetangga dari unit $\mathrm{A}$. 
Rook Contiguity

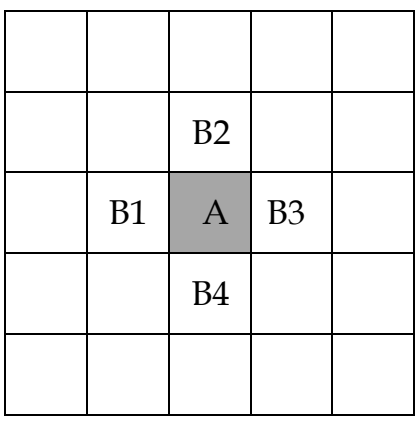

Queen Contiguity

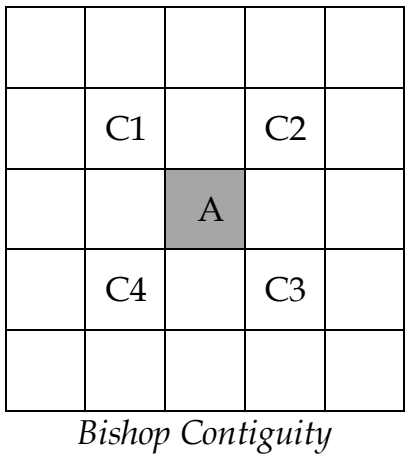

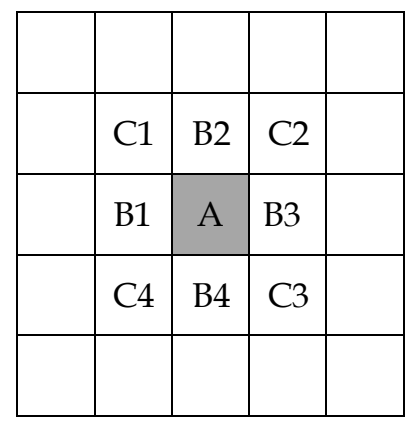

Gambar 5. Grid Umum Ketetanggaan

Model matriks pembobotan yang dipilih dalam penelitian ini adalah Rook Contiguity dan cara memperoleh matriks pembobotan spasial berdasarkan standardize contiguity matrix W (matriks pembobotan standarisasi), yaitu dengan memberikan nilai atau bobot yang sama rata terhadap tetangga terdekat dan yang lainnya diberi bobot nol. Berdasarkan matriks pembobotan spasial, dapat diketahui jumlah tetangga lokasi yang dimiliki oleh masing-masing kecamatan.

Langkah yang dilakukan berikutnya yaitu perhitungan nilai indeks Moran (Moran's I). Metode perhitungan Moran's I dalam analisis Autokorelasi Spasial dapat diaplikasikan untuk mendeteksi feature spasial dengan tujuan mengindikasikan bentuk pola spasial yang berkelompok (clustered), menyebar (dispersed), atau acak (random). Moran's I menghitung perbedaan antara nilai sebuah feature dengan nilai ratarata untuk semua feature dan perbedaan antara nilai feature pada masing-masing tetangga terhadap nilai rata-rata. Formulasi rumusnya sebagai berikut:

$$
\mathrm{I}=\frac{N}{\sum i \sum j W i j} \frac{\sum i \sum j W i j(X i-\bar{X})(X j-\bar{X})}{\sum i(X i-\bar{X})^{2}}
$$

Keterangan:

I $\quad=$ nilai Moran's I

$\mathrm{N} \quad=$ banyaknya lokasi kejadian

$\mathrm{Xi} \quad=$ nilai pada lokasi $\mathrm{i}$

$\mathrm{X}_{\mathrm{j}} \quad=$ nilai pada lokasi $\mathrm{j}$
$\overline{\mathrm{X}} \quad=$ rata-rata jumlah variabel

$\mathrm{Wij}=$ elemen pada pembobotan antara daerah $\mathrm{i}$ dan daerah $\mathrm{j}$

Nilai I yang diperoleh dari hasil perhitungan autokorelasi dapat mengindikasikasikan pola feature yang terbentuk, yaitu: (1) jika I > 0 maka pola yang terbentuk adalah berkelompok (clustered) berarti terdapat banyak kemiripan nilai pada feature; (2) jika I < 0 maka pola yang terbentuk adalah acak (random) berarti pola feature tidak jelas; dan (3) jika I = 0 maka pola yang terbentuk adalah menyebar (dispersed) berarti nilai feature yang tinggi dan rendah menyebar dalam data (Hernawati dan Ardiansyah, 2017).

Selain dapat mengetahui pola feature yang terbentuk dari nilai Moran's I, hasil perhitungan juga dipergunakan untuk menghitung autokorelasi spasial. Ada atau tidaknya autokorelasi spasial dalam sebuah data diuji melalui uji statistik Moran's I dengan memasukkan nilai harapannya. Berdasarkan penelitian Hernawati dan Ardiansyah (2017), tahapan uji statistik tersebut sebagai berikut:

1. Penentuan hipotesis nol (Ho) dan hipotesis alternatif, hipotesis uji satu arah autokorelasi spasial yaitu:

Ho: $\mathrm{I}=0$, artinya tidak ada autokorelasi spasial

Untuk hipotesis alternatifnya yaitu: 
H1: I > 0, artinya terdapat autokorelasi spasial positif

H1: I < 0, artinya terdapat autokorelasi spasial negatif

Ho ditolak jika nilai Z(I) > Z(a) atau Z(I) $<-Z(\alpha)$, sehingga terdapat autokorelasi spasial.

2. Penentuan nilai $Z$ kritis $(Z(\alpha))$, dihitung dengan $a / 2$ untuk derajat kepercayaan 99\%.

3. Penentuan nilai uji $(Z(I))$ dihitung dengan tahapan sebagai berikut:

a. Menghitung nilai harapan statistik (E(I)) menggunakan rumus:

$$
E(I)=\frac{1}{(n-1)}
$$

Keterangan:

$\mathrm{E}(\mathrm{I}) \quad=$ nilai harapan Moran's I

b. Menghitung nilai variansi menggunakan rumus:

$$
\operatorname{VAR}(I)=\frac{n^{2} S^{1}-n S^{2}+3(C)^{2}}{(C)^{2}\left(n^{2}-1\right)}
$$

Dimana:

$$
C=\sum_{i=1}^{n} C \sum_{j=1}^{n} C i j
$$

Keterangan:

Cij = elemen matriks contiguity

$\mathrm{Ci}=$ jumlah nilai baris ke-I matriks contiguity

$\mathrm{Cj}=$ jumlah nilai kolom ke-I matriks contiguity

c. Menghitung nilai uji statistik menggunakan rumus:

$$
Z(I)=\frac{I-E(I)}{\sqrt{\operatorname{VAR(I)}}}
$$

Keterangan:

I = nilai Moran's I

$\mathrm{Z}(\mathrm{I}) \quad=$ nilai statistik uji Moran's I

$\mathrm{E}(\mathrm{I}) \quad=$ nilai harapan Moran's I

VAR $(\mathrm{I})=$ variansi dari Moran's I

4. Pengambilan keputusan yang mengacu pada penerimaan atau penolakan hipotesis nol dan hipotesis alternatif, adapun keputusan yang dapat diambil yaitu:

a. Menerima Ho, bila nilai uji berada di bawah nilai kritis atas;

b. Menerima Ho, bila nilai uji di atas nilai kritis bawah;

c. Menolak Ho, jika nilai uji dibawah nilai kritis bawah;

d. Menolak Ho, jika nilai uji di atas nilai kritis atas.

5. Pengidentifikasian autokorelasi yang terjadi (positif atau negatif).

6. Penggunaan Local Indicator of Spatial Autocorrelation (LISA), yaitu pengidentifikasian koefisien autokorelasi secara lokal atau korelasi spasial pada setiap daerah. Semakin tinggi nilai lokal Moran's I, memberikan informasi bahwa wilayah yang berdekatan memiliki nilai yang hampir sama atau membentu suatu penyebaran yang mengelompok.

7. Pengelompokkan dan penyebaran antarlokasi yang disajikan melalui Moran's Scatterplot yang menunjukkan hubungan antara Zstd (nilai pengamatan yang distandardisasi) dengan nilai rata-rata lokal yang dihitung dari matriks pembobot WZstd (nilai rata-rata lokal yang dihitung dari matriks pembobot spasial) sebagaimana pada Gambar 6. Moran's Scatterplot terbagi menjadi 4 kuadran, Kuadran I (High-High/HH) menunjukkan daerah yang mempunyai nilai pengamatan tinggi dan dikelilingi oleh daerah dengan nilai pengamatan tinggi. Kuadran II (Low-High/LH) menunjukkan daerah dengan pengamatan rendah tetapi dikelilingi oleh daerah dengan nilai pengamatn tinggi. Kuadran III (Low-Low/LL) menunjukkan daerah dengan nilai pengamatan rendah dan dikelilingi oleh daerah dengan nilai pengamatan rendah. Kuadran IV (High-Low/HL) 
menunjukkan daerah dengan nilai pengamatan tinggi yang dikelilingi oleh daerah dengan nilai pegamatan rendah. Moran's Scatterplot yang banyak menempatkan hasil pengamatan di kuadran $\mathrm{HH}$ dan kuadran LL akan cenderung mempunyai nilai autokorelasi spasial yang positif. Sedangkan Moran's Scatterplot yang banyak menempatkan pengamatan di kuadran HL dan LH akan cenderung mempunyai nilai autokorelasi spasial yang negatif. Untuk memperjelas hasil analisis, maka posisi masing-masing pengamatan pada Moran's Scatterplot dapat dipetakan pada masing-masing letak geografis dalam suatu peta tematik.

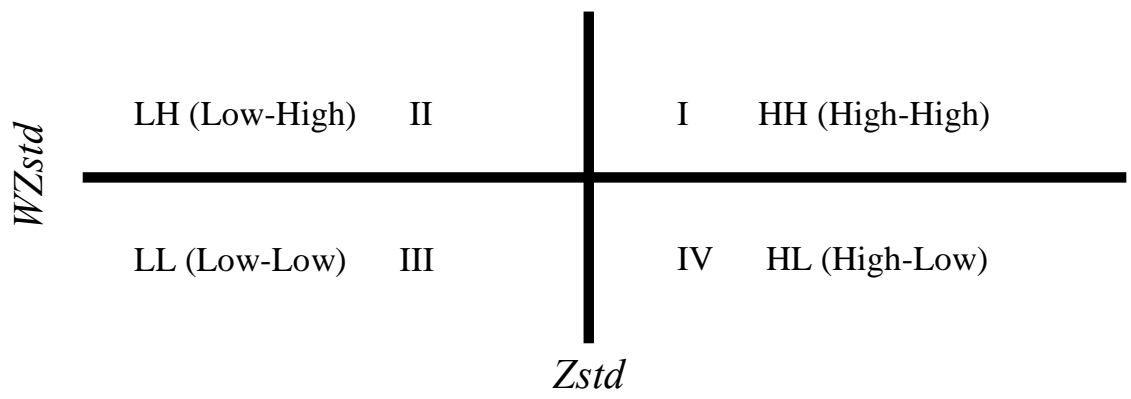

Gambar 6. Ilustrasi nilai Zstd dan WZstd pada Moran's Scatterplot

\section{HASIL DAN PEMBAHASAN \\ Analisis Deskriptif Terhadap Data}

Berdasarkan data luasan Kawasan LP2B sebagaiaman dimuat dalam Tabel 1, dapat diketahui bahwa pada 30 kecamatan di Kabupaten Karawang memiliki data yang beragam, dengan rata-rata luasan 3.255 hektar per-kecamatan. Secara spasial klasifikasi persebaran luasan LP2B disajikan daalam Gambar 7. Kecamatan-kecamatan yang termasuk dalam klasifikasi luasan rendah $(<2.430$ ha) terdiri atas 12 kecamatan yaitu Rengasdengklok, Karawang Barat, Karawang Timur, Majalaya, Klari, Purwasari, Cikampek, Kotabaru, Ciampel, Telukjambe Timur, Telukjambe Barat, dan Pangkalan. Kecamatan-kecamatan tersebut berada pada bagian tengah-selatan di Kabupaten Karawang, yang berdekatan dengan penggunaan lahan industri/direncanakan menjadi kawasan industri, penggunaan lahan permukiman/direncanakan menjadi kawasan permukiman perkotaan, dan berdekatan dengan sarana transportasi primer. Sementara kecamatan-kecamatan yang termasuk dalam klasifikasi luasan sedang (2.431 - 4.861 ha) terdiri atas 11 kecamatan yaitu Pakisjaya, Batujaya, Jayakerta, Kutawaluya, Rawamerta, Talagasari, Lemahabang, Tirtamulya, Banyusari, Jatisari, dan Tegalwaru. Kecamatan-kecamatan tersebut berada pada bagian tengah-utara di Kabupaten Karawang. Klasifikasi luasan tinggi (> 4.862 ha) terdiri atas 7 kecamatan yaitu Tirtajaya, Cibuaya, Pedes, Cilebar, Tempuran, Cilamaya Kulon, dan Cilamaya Wetan. Kecamatan-kecamatan tersebut berada pada bagian utara di Kabupaten Karawang.

\section{Hasil Perhitungan Autokorelasi Spasial}

Hasil yang diperoleh dari penelitian ini yaitu berupa informasi mengenai kecamatan-kecamatan yang berada di Kabupaten Karawang yang memiliki luasan Kawasan LP2B saling berkorelasi antara satu kecamatan dengan yang lainnya. Berdasarkan data luasan Kawasan LP2B dimaksud, terbentuk pola-pola mengelompok pada lokasi tertentu. Hasil perhitungan autokorelasi spasial 
diilustrasikan dalam Gambar 8 dan Tabel 2. Hasil perhitungan autokorelasi spasial dengan menggunakan metode Moran's I, ditemukan parameter-parameter. Pada tahap pertama, parameter yang dianalisis adalah nilai Moran's I yaitu sebesar 0,688385 , nilai tersebut berada pada rentang $0<$ I $<1$ maka disimpulkan bahwa autokorelasi yang terjadi adalah autokorelasi spasial positif. Autokorelasi positif mengindikasikan lokasi yang berdekatan memiliki nilai yang mirip dan besaran luasan Kawasan LP2B di Kabupaten Karawang cenderung berkelompok (clustered). Dalam analisis digunakan ketentuan ketetanggan berdasarkan kecamatan, oleh karena itu kelompok yang dimaksud merupakan kecamatan yang berkelompok berdasarkan besaran luasan Kawasan LP2B yang hampir sama.

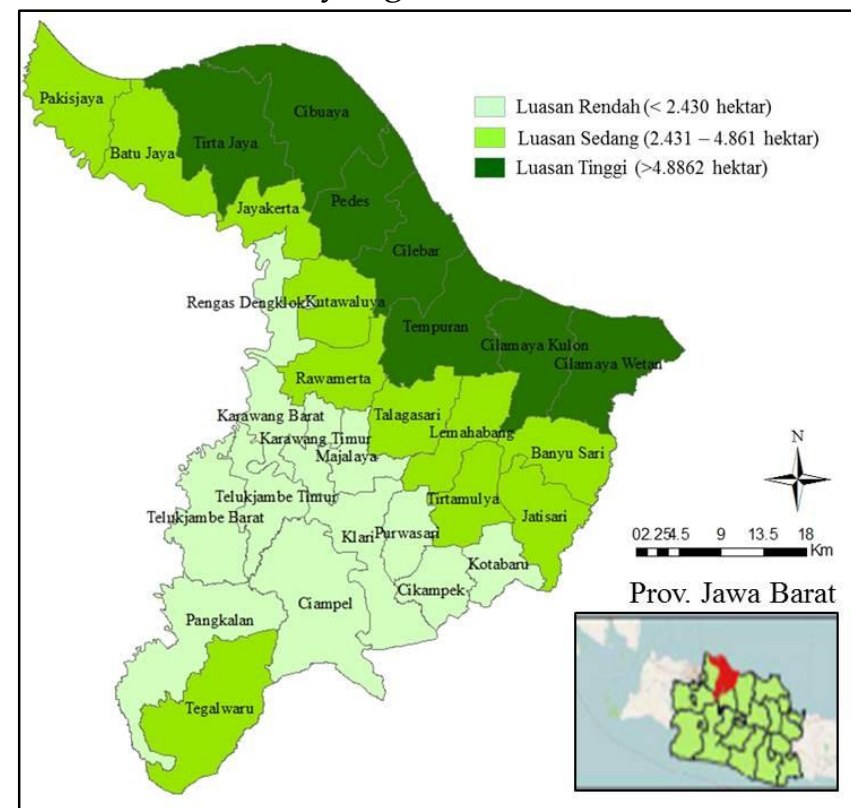

Gambar 7. Tingkat Persebaran Luasan Kawasan LP2B di Kabupaten Karawang

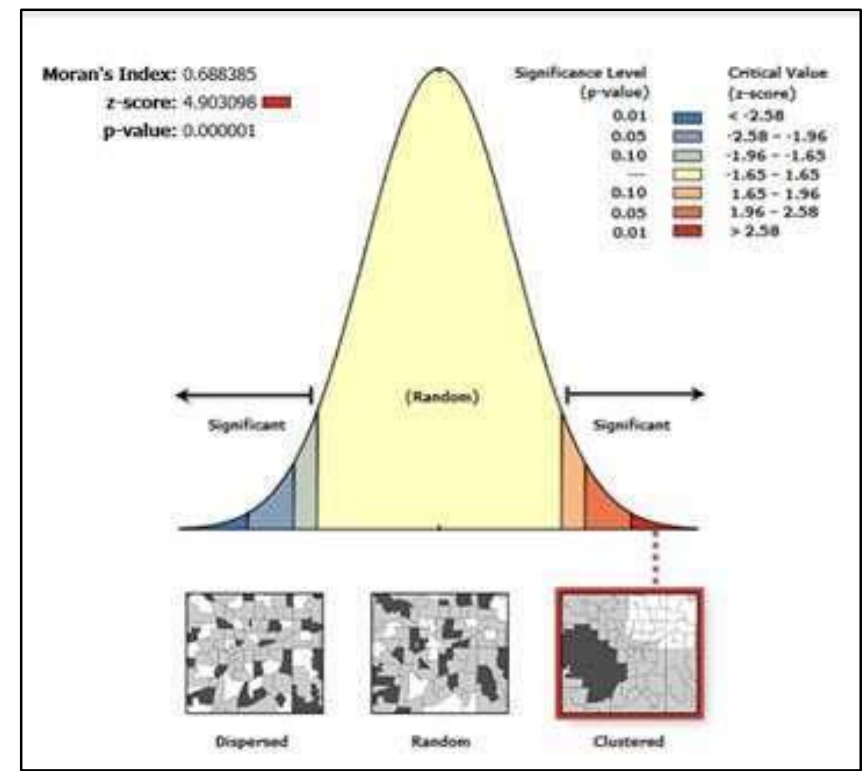

Gambar 8. Hasil Perhitungan Autokorelasi Spasial Menggunakan Moran's I 
Tabel 2. Uji Statistik Moran's I pada Persebaran Luasan Kawasan LP2B

\begin{tabular}{|c|c|c|c|c|c|c|}
\hline Moran's I & $\begin{array}{c}\text { Nilai } \\
\text { Harapan } \\
(\mathrm{E}(\mathrm{I}))\end{array}$ & $\begin{array}{r}\text { Variansi } \\
(\operatorname{VAR}(\mathrm{I}))\end{array}$ & $\begin{array}{l}\text { Z-score } \\
(\mathrm{Z}(\mathrm{I}))\end{array}$ & $\begin{array}{l}\text { Z-kritis } \\
(\mathrm{Z}(\mathrm{a}))\end{array}$ & P-value & Uji Statistik \\
\hline \multirow{2}{*}{0,688385} & \multirow{2}{*}{$-0,034483$} & \multirow{2}{*}{0,021736} & \multirow{2}{*}{ 4,903098 } & \multirow{2}{*}{2,58} & \multirow{2}{*}{0,000001} & $\begin{array}{l}4,903098>2,58 \Leftrightarrow Z(I)>Z(a) \\
\text { Maka Ho ditolak }\end{array}$ \\
\hline & & & & & & $\begin{array}{l}0,688385>0 \\
\text { Maka } \mathrm{H}_{1} \text { diterima }\end{array}$ \\
\hline
\end{tabular}

Sumber : Pengolahan Data, 2020

Setelah mengetahui hasil perhitungan dalam autokorelasi spasial, kita dapat melakukan uji statistik persebaran luasan Kawasan LP2B. Berdasarkan nilai Pvalue dapat dilihat signifikansi pengaruh antardaerah secara spasial, yang dalam penelitian ini uji statistik dilakukan pada tingkat signifikansi 5\% $(0,05)$. Dari hasil uji statistik didapatkan P-value sebesar 0,000001, yaitu kurang dari a $=0,05$, sehingga disimpulkan bahwa daerahdaerah yang menjadi obyek penelitian memberikan pengaruh spasial secara signifikan. Analisis yang dilakukan selanjutnya yaitu pengujian hipotesis, didapatkan bahwa nilai Moran's I $\neq 0$ maka Ho ditolak namun H1 diterima. Sementara itu penguian hipotesis selanjutnya dengan memerhatikan nilai Z-score $(Z(I))$ dan Zkritis $(Z(\alpha))$, yang dalam penelitian ini dihasilkan bahwa $Z(I)>Z(\alpha)$ disimpulkan sebagai penolakan Ho, yaitu bahwa berdasarkan data spasial yang dianalisis, terjadi autokorelasi spasial.

Setelah melakukan pengujian autokorelasi spasial secara global menggunakan Moran's I, perlu dilakukan pengujian secara lokal untuk melihat lokasi mana saja yang memiliki autokorelasi spasial. Dalam penelitian ini, pengujian secara lokal dilakukan dengan menggunakan analisis Local Indicator of Spatial Autocorrelation (LISA) dan pembobotan yang dipilih adalah Rook Contiguity, yang kemudian didapatkan 2 (dua) hasil analisis, yaitu:

\section{Moran's Scatterplot}

Pada Moran's Scatterplot tersusun oleh 2 (dua) variabel, yaitu Zstd (nilai pengamatan yang distandardisasi) dan WZstd (nilai rata-rata lokal yang dihitung dari matriks pembobot spasial). Zstd berupa jumlah luasan Kawasan LP2B berdasarkan kecamatan yang telah distandardisasi dan WZstd berupa rata-rata pembobotan dari jumlah luasan Kawasan LP2B berdasarkan kecamatan. Pada Gambar 9 tampak titik-titik yang tersebar pada 4 (empat) kuadran yang berbeda. Persebaran titik dimaksud sebagian besar berada di sekitar slope, artinya standar deviasi dari data yang digunakan dalam penelitian ini cukup kecil, sehingga signifikan dalam menunjukkan ketetanggaan spasial. Titik-titik yang tersebar, terlihat jumlah yang seimbang berkelompok pada kuadran I (High-High) dan kuadran III (Low-Low).

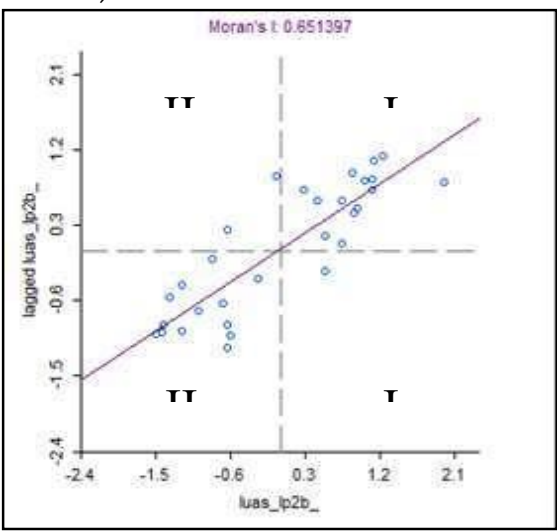

Gambar 9. Moran's Scatterplot Persebaran Luasan Kawasan LP2B 


\section{LISA Cluster Map}

Setelah mengetahui persebaran luasan Kawasan LP2B yang terklasterisasi dalam kuadran sifat ketanggaan, kita juga dapat mengetahui pola spasial persebarannya yang divisualisasikan dalam peta (Gambar 10). Hasil sebaran nilai-nilai dalam pengamatan adalah sebagai berikut:

a. Kuadran I (High-High): kecamatan yang didefinisikan dalam nilai ini terdiri atas 6 kasus, yaitu Pedes, Jayakerta, Cilebar, Tempuran, Cilamaya Kulon, dan Cilamaya Wetan. Kecamatan-kecamatan tersebut memiliki jumlah luasan Kawasan LP2B tinggi dan dikelilingi oleh kecamatan lain yang memiliki jumlah luasan Kawasan LP2B yang tinggi pula. b. Kuadran II (Low-High): kecamatan yang didefinisikan dalam nilai ini tidak ada.

c. Kuadran III (Low-Low): kecamatan yang didefinisikan dalam nilai ini terdiri atas 6 kasus, yaitu Telukjambe Barat, Telukjambe Timur, Karawang Timur, Ciampel, Klari, dan Cikampek. Kecamatankecamatan tersebut memiliki jumlah luasan Kawasan LP2B rendah dan dikelilingi oleh kecamatan lain yang memiliki jumlah luasan Kawasan LP2B yang rendah pula.

d. Kuadran IV (High-Low): kecamatan yang didefinisikan dalam nilai ini tidak ada.

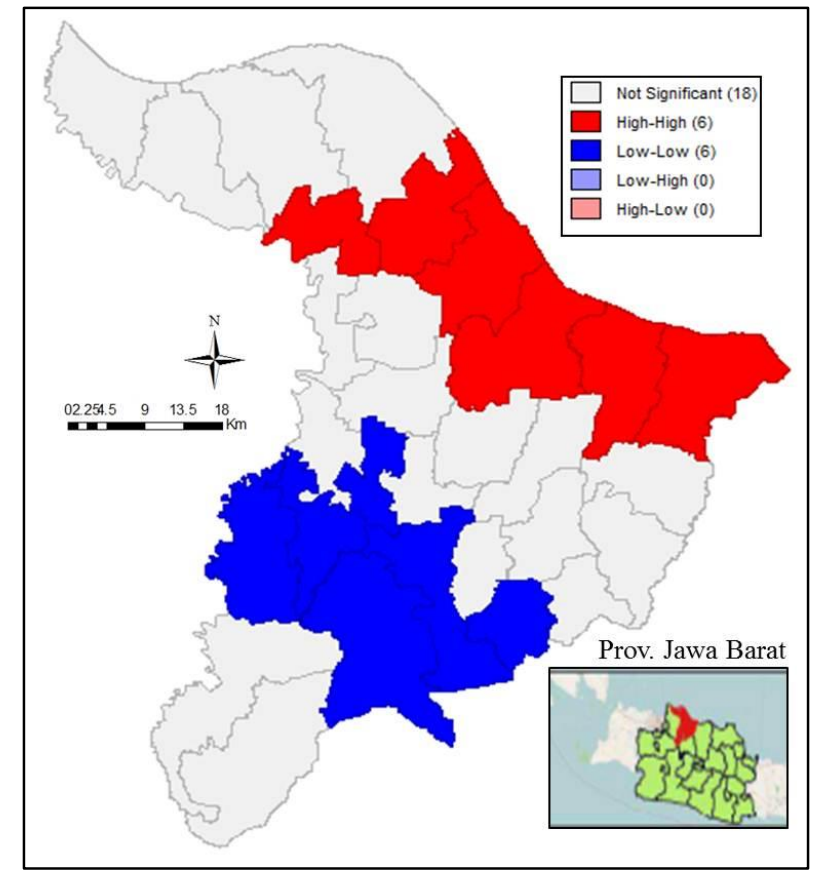

Gambar 10. Klasterisasi Pola Persebaran Spasial

Luasan Kawasan LP2B

\section{KESIMPULAN}

Analisis autokorelasi spasial terhadap persebaran luasan Kawasan LP2B di Kabupaten Karawang, menghasilkan kesimpulan bahwa terdapat autokorelasi spasial bersifat positif dengan pola sebaran mengelompok (clustered), yang didefinisikan dalam 2 tipologi hubungan pengelompokan yaitu high-high dan low-low. Hubungan yang terjadi pada persebaran luasan Kawasan LP2B ini membuktikan adanya pengaruh rencana pola ruang dalam Peraturan Daerah 


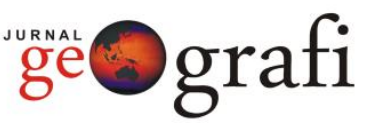

Kabupaten Karawang Nomor 2 Tahun 2013 tentang Rencana Tata Ruang Wilayah Kabupaten Karawang 2011-2031 (Perda RTRW) dalam mengatur fungsi kawasan di Kabupaten Karawang. Penetapan Kawasan LP2B mengadaptasi perkembangan kutubkutub pertumbuhan ekonomi non-pertanian secara keruangan, yang disesuaikan dengan penggunaan lahan saat ini. Hal ini merupakan langkah positif untuk menghindari pelanggaran penggunaan lahan yang telah ditetapkan dalam Perda RTRW. Penelitian ini diharapkan sebagai langkah awal untuk menganalisis reliabilitas sebuah rencana tata ruang dalam mengadaptasi pertumbuhan wilayahnya, namun demikian masih diperlukan analisis lanjutan dalam korelasi keruangan. Analisis lanjutan yang disarankan khususnya dikaitkan dengan produktifitas Kawasan LP2B untuk merespon peran Kabupaten Karawang sebagai salah satu lumbung padi nasional.

\section{UCAPAN TERIMA KASIH}

Penulis mengucapkan terima kasih kepada Kementerian Agraria dan Tata Ruang/Badan Pertanahan Nasional, Kantor Pertanahan Kabupaten Karawang, Dinas Pertanian Kabupaten Karawang, dan Badan Perencanaan dan Pembangunan Daerah Kabupaten Karawang, yang telah memberikan kemudahan dalam mengakses data yang menunjang penelitian ini. Ucapan terima kasih juga penulis sampaikan kepada Pusbindiklatren Bappenas yang telah mendanai penelitian ini.

\section{DAFTAR PUSTAKA}

[BPS] Badan Pusat Statistik. (1990). Statistik Indonesia 1990. Badan Pusat Statistik. Jakarta.

[BPS] Badan Pusat Statistik. (2018). Statistik Indonesia 2018. CV. Dharmaputra. Jakarta.

[BPS] Badan Pusat Statistik Kabupaten Karawang. (2018). Kabupaten Karawang dalam Angka. CV. Daun Kreatif. Karawang.

[BPS] Badan Pusat Statistik. (2019). Statistik Indonesia 2019. Badan Pusat Statistik. Jakarta.

Kosfeld, R., \& Dreger, C. (2006). Treshhold for employment and unemployment: A Spatial Analysis of German Regional Labour Markets, 1992-2000. Paper in Regional Science, 85(4), 523-542.

Kustiwan, I. (1997). Permasalahan konversi lahan pertanian dan implikasinya terhadap penataan ruang wilayah studi kasus: wilayah pantura Jawa Barat. Jurnal PWK, $8(1), 49-60$.

Muta'ali, L. (2015). Teknik Analisis Regional Untuk Perencanaan Wilayah, Tata Ruang dan Lingkungan. Badan Penerbit Fakultas Geografi UGM, Yogyakarta.

Peraturan Daerah Kabupaten Karawang. (2013). Rencana Tata Ruang Wilayah Kabupaten Karawang 2011-2031. Peraturan Daerah Nomor: 2 Tahun 2013. Bappeda Kabupaten Karawang. Karawang.

Peraturan Daerah Kabupaten Karawang. (2018). Perlindungan Lahan Pertanian Pangan Berkelanjutan. Peraturan Daerah Nomor: 1 Tahun 2018. Bappeda Kabupaten Karawang. Karawang.

Pribadi, D.O., Zasada, I., Muller, K., Pauleit, S. (2017). Multifunctional adaption of farmers as response to urban growth in the jabodetabek metropolitan area, indonesia. Journal of Rural Studies, 55, 100-111.

RI (Republik Indonesia). (2007). UndangUndang Nomor 26 Tahun 2007 tentang Penataan Ruang. Lembaran Negara RI Tahun 2007, No. 68. Sekretariat Negara. Jakarta.

RI (Republik Indonesia). (2009). UndangUndang Nomor 41 Tahun 2009 tentang Perlindungan Lahan Pertanian Pangan Berkelanjutan. Lembaran Negara RI Tahun 2009, No. 149. Sekretariat Negara. Jakarta.

Wahyunto. (2009). Lahan sawah di Indonesia sebagai pendukung ketahanan pangan nasional. Informatika Pertanian, 18(2), 133152. 